\title{
Leaving EMU: a real options perspective
}

\author{
Frank Strobel \\ Dept. of Economics \\ Univ. of Birmingham \\ Birmingham B15 2TT, UK \\ Preliminary draft version: May 10, 2004
}

\begin{abstract}
We examine the real option implicit in a country's decision of whether to leave an existing monetary union when there is uncertainty over the future benefits of this move. Our theoretical model is calibrated for the current Euro-12 area by proxying policymakers' inflation preferences with unemployment rates and debt-to-GDP ratios. We observe a robust group of countries that would choose to remain within EMU consisting of Belgium, Finland, Greece and Italy; France and Spain loosely also belong to this core. Only Luxembourg would robustly want to leave EMU; Ireland and the Netherlands, however, complement that core closely.

Keywords: EMU; real option; calibration

JEL classification: E5, F3
\end{abstract}

\section{Introduction}

The European Monetary Union (EMU) has only been in operation since 1 January 1999, yet some of the current member countries may already be considering whether or not a return to monetary independence might be 
preferable. Policymakers are concerned about inflation performance, possibly because a time inconsistency problem in monetary policymaking can cause an undesirable inflation bias to persist. ${ }^{1}$ If the future evolution of such inflation preferences is uncertain, it may have a significant impact on the decision to leave the union because of policymakers' reluctance to commit to a largely irreversible move that might later prove less advantageous than initially thought. This value of waiting, arising from the real options nature of this problem, is well-known from the literature on irreversible investment under uncertainty, can be substantial and needs to be properly accounted for. $^{2}$

Several papers have begun to address these issues. Strobel (in press), in a two-country model where policymakers minimize loss functions over inflation and inflation preferences follow geometric Brownian motions, solves the optimal stopping problem that describes a country's decision of whether to pursue monetary integration with the other one, and gives conditions under which monetary integration can, or will never, be an equilibrium outcome. More partial frameworks are used in Strobel (2001), which examines the value of the option of monetary disintegration for a country in an existing monetary union when inflation preferences follow a similar stochastic process, and Strobel (2002), which extends the previous paper by deriving closed-form solutions of the expected time and probability for a country in an existing monetary union to want to return to monetary independence under such circumstances.

Our present paper builds on and applies the theoretical model of Strobel (in press) in examining the real option implicit in a country's decision of whether or not to leave a monetary union when the costs of later rejoining it are considered prohibitively high and there is uncertainty over the future benefits of such a move. We show that a country perceives exercise of this option of monetary disintegration as desirable only when the current value of relative inflation preference parameters is larger than a specific trigger value; intuitively, the lower a country's inflation preference relative to the existing

\footnotetext{
${ }^{1}$ See e.g. Barro/Gordon (1983a,b).

${ }^{2}$ See e.g. Dixit/Pindyck (1994).
} 
union's, the more it stands to gain from returning to monetary independence. We then calibrate our theoretical model for the current Euro-12 area by proxying policymakers' inflation preference parameters with both unemployment rates and debt-to-GDP ratios. Using annual data from OECD (2003), we derive the proxied trigger values of relative inflation preference parameters for time horizons of 50, 25 and 10 years to allow for differing degrees of policymakers' myopia and contrast them with the corresponding actual ratios for 2002 and 2003 (predicted), our two reference periods.

Across the two proxies used, we observe a robust group of countries that would choose to remain within EMU consisting of Belgium, Finland, Greece and Italy; France and Spain generally also belong to this core but for the 10 year horizon using the debt-to-GDP ratio proxy. Luxembourg emerges as the only country that would robustly want to leave EMU across both proxies; Ireland and the Netherlands, however, complement that core except for the 50 year horizon in the 2003 reference period using the unemployment rate proxy. The cases for Austria, Germany and Portugal, by contrast, are significantly less clear cut, as their decisions of whether or not to exercise the option of leaving EMU are seen to depend crucially on which particular proxy and time horizon is used.

Section 2 now presents the model; the results of our calibration exercise are reported in section 3 , and section 4 concludes the paper.

\section{The model}

The national and supranational policymakers' objectives, for countries $c$ and the union $u$, entail the instantaneous loss rate

$$
l_{i t}=\pi_{i t}^{2}-\eta_{i t}\left(\pi_{i t}-\pi_{i t}^{e}\right) \quad, \quad i=c, u
$$

where $\pi_{i t}$ and $\pi_{i t}^{e}$ are inflation and expected inflation, respectively. ${ }^{3}$

Policymakers' inflation preference (or benefit) parameters $\eta_{i t} \geq 0$ are

\footnotetext{
${ }^{3}$ This adapts the setup in Barro/Gordon (1983a); similar frameworks are used in Strobel (2001, 2002, in press).
} 
assumed to follow geometric Brownian motions ${ }^{4}$

$$
d \eta_{i t}=\sigma_{i} \eta_{i t} d z_{i t}
$$

where $\sigma_{i}>0, d z_{i t} \sim \mathrm{NID}(0, d t)$ are increments of Wiener processes, and $E_{t}\left(d z_{c t} d z_{u t}\right)=\rho_{c u} d t$ with $-1<\rho_{c u}<1$ the coefficient of correlation between the processes $z_{i}$.

We focus on a discretionary policy scenario under rational expectations where policymakers solve for the optimal feedback rule $\pi_{i}^{*}\left(\eta_{i}\right)$ that satisfies the loss function

$$
L_{i t}=\min _{\pi_{i}} E_{t} \int_{t}^{\infty} l_{i \tau} e^{-\mu(\tau-t)} d \tau \quad, \quad i=c, u
$$

with $\mu>0$ the common discount rate, treating inflationary expectations $\pi_{i \tau}^{e}$ as given $\forall \tau \geq t$. We then obtain

Lemma 1 In a rational expectations equilibrium, the loss functions for the national and supranational policymakers are

$$
L_{i t}=\frac{1}{4\left(\mu-\sigma_{i}^{2}\right)} \eta_{i t}^{2} \quad, \quad i=c, u
$$

for $\mu-\sigma_{i}^{2}>0$.

Proof. Analogous to the proof for Lemma 2 in Strobel (in press).

A country $c$ deciding on whether or not to leave the monetary union $u$ then solves the Bellman equation for the optimal stopping problem

$$
F\left(L_{u}, L_{c}\right)=\max \left\{L_{u}-L_{c}, \frac{1}{\mu d t} E_{t}\left[d F\left(L_{u}, L_{c}\right)\right]\right\}
$$

where $F\left(L_{u}, L_{c}\right)$ is the value to country $c$ of the option of leaving the monetary union $u$, and $L_{u}-L_{c}$ is the expected discounted benefit of such a move when any other cost/benefits are abstracted from. ${ }^{5}$ Note that this implicitly

\footnotetext{
${ }^{4}$ There is no consensus over whether inflation follows a non-stationary or a stationary process, see e.g. Culver/Papell (1997), Lai (1997); a geometric Brownian motion is used for analytical ease.

${ }^{5}$ We drop time subscripts for ease of notation.
} 
assumes that leaving a monetary union is an irreversible process, so that the costs of possibly later rejoining it are considered prohibitively high. We can then obtain

Proposition 2 Country $c$ will want to exercise the option of leaving the monetary union $u$ if

$$
\begin{aligned}
\frac{\eta_{u}}{\eta_{c}} & >\left(\frac{\eta_{u}}{\eta_{c}}\right)^{\star}=\sqrt{\frac{2 \mu+\sigma_{u}^{2}-4 \rho_{c u} \sigma_{u} \sigma_{c}+\sigma_{c}^{2}+\Theta}{2\left(\mu-\sigma_{c}^{2}\right)}} \\
\text { where } \Theta & =\sqrt{\left(\sigma_{u}^{2}-\sigma_{c}^{2}\right)^{2}+8\left(\mu-\rho_{c u} \sigma_{u} \sigma_{c}\right)\left(\sigma_{u}^{2}-2 \rho_{c u} \sigma_{u} \sigma_{c}+\sigma_{c}^{2}\right)}
\end{aligned}
$$

and not exercise it otherwise.

Proof. See Appendix.

Country $c$ perceives exercise of the option to leave the monetary union $u$ as desirable only when the current value of relative inflation preference parameters $\frac{\eta_{u}}{\eta_{c}}$ is greater than its trigger value $\left(\frac{\eta_{u}}{\eta_{c}}\right)^{\star}$; intuitively, the lower a country's inflation preference relative to the union's, the more it stands to gain from returning to monetary independence. For the case where $\frac{\eta_{u}}{\eta_{c}} \leq$ $\left(\frac{\eta_{u}}{\eta_{c}}\right)^{\star}$, on the other hand, country $c$ prefers to leave the option of monetary disintegration unexercised and remains within the union for the time being.

\section{A simple calibration}

We proceed to calibrate the model in Section 2 for the current twelve members of the Eurozone, proxying policymakers' inflation preference (or benefit) parameters $\eta_{i}$ with both unemployment rates and debt-to-GDP ratios. These particular measures are chosen to reflect two widely cited rationales for the potential benefits of surprise inflation, as embodied in eq. (1), the expectational Phillips curve and governmental revenue motives. ${ }^{6}$

Using annual data from Annex Tables 14 and 33 in OECD (2003), we calculate the required moments $\sigma_{i}$ and $\rho_{c u}$ from the respective transformed

\footnotetext{
${ }^{6}$ See e.g. Barro/Gordon (1983b) and Barro (1983), respectively.
} 
series $\ln \left(\frac{x_{t}}{x_{t-1}}\right)$ to allow for our distributional assumption of eq. (4). We then compute the proxied trigger values of relative inflation preference parameters $\left(\frac{\eta_{u}}{\eta_{c}}\right)^{\star}$, from Proposition 2, for time horizons of 50, 25 and 10 years by applying discount rates $\mu$ of $3.5 \%, 5.4 \%$ and $11.3 \%$, respectively. ${ }^{7}$ These results are presented in Tables 1 and 2, together with the proxied values for the relative inflation preference parameters $\frac{\eta_{u}}{\eta_{c}}$ for 2002 and 2003 (predicted), our two reference periods; in each case, we highlight in bold (italics) those values consistent with country c's exercise (non-exercise) of the option of leaving the monetary union $u$, i.e. EMU, at all three time horizons.

For the unemployment rate proxy, we observe from Table 1 that a core group of countries comprising Belgium, Finland, France, Germany, Greece, Italy and Spain would prefer to remain within EMU irrespective of the time horizon or reference period considered; this criterion provides a certain degree of robustness. Portugal is also largely inclined to stay within EMU; it would leave the union only for the 10 year horizon in the 2002 reference period. The duo of Austria and Luxembourg, on the other hand, would choose to exercise their options of leaving EMU for all time horizons and reference periods, generating a second robust grouping. Ireland and the Netherlands are also generally biased towards leaving EMU, except for the 50 year horizon in the 2003 reference period where they would both stay put.

Results somewhat change when the debt-to-GDP ratio proxy is used. Table 2 indicates that for this measure the robust group of countries preferring to stay within EMU irrespective of time horizon or reference period now consists of Belgium, Finland, Greece and Italy only. Austria, France and Spain would also largely choose to remain within EMU in this case; only for the 10 year horizon would they exercise their respective options of leaving the union. The opposing robust group of countries preferring to leave EMU for all time horizons and reference periods, by contrast, now consists of Ireland, Luxembourg and the Netherlands. In addition, Germany and Portugal would also generally be inclined to leave EMU in this scenario, but for the 50 year horizon where they would both stick to the status quo.

\footnotetext{
${ }^{7}$ Given our infinite horizon framework, these approximate the application of a (real) discount rate $r$ of $2.5 \%$ over those finite time horizons $T$, using $\mu=\frac{r}{1-e^{-r T}}$.
} 


\begin{tabular}{lrrrrrrr}
\hline & St.dev. & Corr. $\mathrm{w} / \mathrm{u}$ & Trigger u/c & \multicolumn{3}{c}{ Ratios u/c } \\
\hline & & & $50 \mathrm{yrs}$ & $25 \mathrm{yrs}$ & $10 \mathrm{yrs}$ & 2002 & $2003(\mathrm{P})$ \\
Austria & & & & & & & \\
Belgium & 0.07 & 0.64 & 1.29 & 1.22 & 1.15 & 1.54 & 1.47 \\
Finland & 0.11 & 0.91 & 1.34 & 1.23 & 1.14 & 1.14 & 1.12 \\
France & 0.28 & 0.60 & inf. & inf. & 2.68 & 0.90 & 0.95 \\
Germany & 0.07 & 0.93 & 1.12 & 1.09 & 1.06 & 0.93 & 0.94 \\
Greece & 0.10 & 0.89 & 1.30 & 1.21 & 1.13 & 1.06 & 1.06 \\
Ireland & 0.07 & 0.49 & 1.35 & 1.26 & 1.17 & 0.82 & 0.92 \\
Italy & 0.13 & 0.67 & 1.80 & 1.50 & 1.28 & 1.97 & 1.74 \\
Luxembourg & 0.07 & 0.70 & 1.25 & 1.19 & 1.13 & 0.91 & 0.96 \\
Netherlands & 0.13 & 0.89 & 1.65 & 1.40 & 1.22 & 2.79 & 2.22 \\
Portugal & 0.15 & 0.76 & 2.23 & 1.66 & 1.33 & 3.34 & 2.13 \\
Spain & 0.11 & 0.68 & 2.75 & 1.83 & 1.40 & 1.62 & 1.36 \\
Euro area & 0.08 & 1.00 & 1.31 & 1.21 & 1.12 & 0.73 & 0.73 \\
\hline
\end{tabular}

Source: OECD (2003), Annex Table 14, Unemployment rates: commonly used definitions (per cent of labour force); annual data 1986-2002; moments calculated from transformed series $\ln (\mathrm{x}(\mathrm{t}) / \mathrm{x}(\mathrm{t}-1))$. 50/25/10 year time horizons approximated by 3.5/5.4/11.3\% discount rates. Bold/italic ratios indicate exercise/non-exercise at all time horizons.

Table 1: Unemployment rate: triggers/ratios

Comparing our results across the two proxies used, we then observe a robust group of countries that would choose to remain within EMU consisting of Belgium, Finland, Greece and Italy; France and Spain generally also belong to this core but for the 10 year horizon using the debt-to-GDP ratio proxy. Luxembourg emerges as the only country that would robustly want to leave EMU across both proxies; Ireland and the Netherlands, however, complement that core except for the 50 year horizon in the 2003 reference period using the unemployment rate proxy. The cases for Austria, Germany and Portugal, by contrast, are significantly less clear cut, as their decisions of whether or not to exercise the option of leaving EMU are seen to depend crucially on which particular proxy and time horizon is used.

\section{Conclusion}

We examined the real option implicit in a country's decision of whether to leave an existing monetary union when the costs of later rejoining it are considered prohibitively high and there is uncertainty over the future ben- 


\begin{tabular}{lrrrrrrr}
\hline & St.dev. & Corr. w/ u & Trigger u/c & \multicolumn{3}{c}{ Ratios u/c } \\
\hline & & & $50 \mathrm{yrs}$ & $25 \mathrm{yrs}$ & $10 \mathrm{yrs}$ & 2002 & $2003(\mathrm{P})$ \\
& & & & & & & \\
Austria & 0.04 & 0.30 & 1.19 & 1.15 & 1.10 & 1.11 & 1.14 \\
Belgium & 0.03 & 0.63 & 1.11 & 1.09 & 1.06 & 0.71 & 0.74 \\
Finland & 0.19 & 0.49 & inf. & 2.68 & 1.66 & 1.59 & 1.66 \\
France & 0.05 & 0.81 & 1.15 & 1.12 & 1.08 & 1.12 & 1.09 \\
Germany & 0.06 & 0.71 & 1.20 & 1.15 & 1.10 & 1.20 & 1.17 \\
Greece & 0.08 & 0.48 & 1.38 & 1.28 & 1.17 & 0.72 & 0.74 \\
Ireland & 0.07 & 0.52 & 1.33 & 1.25 & 1.16 & 2.23 & 2.38 \\
Italy & 0.04 & 0.67 & 1.12 & 1.09 & 1.06 & 0.62 & 0.63 \\
Luxembourg & 0.10 & 0.72 & 1.55 & 1.38 & 1.23 & 13.01 & 13.85 \\
Netherlands & 0.04 & 0.67 & 1.14 & 1.11 & 1.07 & 1.42 & 1.45 \\
Portugal & 0.06 & 0.13 & 1.30 & 1.23 & 1.15 & 1.29 & 1.29 \\
Spain & 0.07 & 0.78 & 1.25 & 1.19 & 1.12 & 1.14 & 1.18 \\
Euro area & 0.03 & 1.00 & & & & & \\
\hline
\end{tabular}

Source: OECD (2003), Annex Table 33, General government gross financial liabilities (per cent of nominal GDP); annual data 1985-2002 (except Ireland, Luxembourg 1990-2002); moments calculated from transformed series $\ln (\mathrm{x}(\mathrm{t}) / \mathrm{x}(\mathrm{t}-1)) .50 / 25 / 10$ year time horizons approximated by $3.5 / 5.4 / 11.3 \%$ discount rates. Bold/italic ratios indicate exercise/non-exercise at all time horizons.

Table 2: Debt-to-GDP ratio: triggers/ratios

efits of such a move. Our theoretical model was calibrated for the current Euro-12 area by proxying policymakers' inflation preferences with both unemployment rates and debt-to-GDP ratios. Across the two proxies used, we observed a robust group of countries that would choose to remain within EMU consisting of Belgium, Finland, Greece and Italy; France and Spain loosely also belonged to this core. Luxembourg emerged as the only country that would robustly want to leave EMU across both proxies; Ireland and the Netherlands, however, complemented that core closely. The cases for Austria, Germany and Portugal, by contrast, were significantly less clear cut; their decisions of whether or not to exercise the option of leaving EMU were seen to depend crucially on the particular proxy and time horizon used.

\section{Appendix}

Proof. (Proposition 2) For country $c$, not leaving the monetary union $u$ for a further instant $d t$ is optimal in the continuation region of the optimal 
stopping problem eq. (5), giving the relevant Bellman equation as

$$
\mu F\left(L_{u}, L_{c}\right)=\frac{1}{d t} E_{t}\left[d F\left(L_{u}, L_{c}\right)\right]
$$

Applying Ito's Lemma to eq. (6) and noting that the value function $F\left(L_{u}, L_{c}\right)$ should be homogeneous of degree $1,{ }^{8}$ so that $F\left(L_{u}, L_{c}\right)=L_{c} f(\Gamma)$ where $\Gamma \equiv \frac{L_{u}}{L_{c}},{ }^{9}$ we obtain

$$
\begin{aligned}
-f(\Gamma)\left(\mu-{\sigma_{c}}^{2}\right)+\left({\sigma_{u}}^{2}\right. & \left.-{\sigma_{c}}^{2}\right) \Gamma f^{\prime}(\Gamma) \\
& +2\left(\sigma_{u}{ }^{2}-2 \rho_{c u} \sigma_{u} \sigma_{c}+\sigma_{c}{ }^{2}\right) \Gamma^{2} f^{\prime \prime}(\Gamma)=0
\end{aligned}
$$

as the differential equation that characterizes the evolution of $f(\Gamma)$ in that region.

We solve eq. (7) by standard methods, using the value-matching and smooth-pasting conditions $f\left(\Gamma^{*}\right)=\Gamma^{*}-1$ and $\frac{\partial f\left(\Gamma^{*}\right)}{\partial \Gamma}=1$, plus the boundary condition $f(0)=0,{ }^{10}$ and thus obtain

$$
\begin{aligned}
& \Gamma^{*}=\frac{\gamma_{1}}{\gamma_{1}-1} \\
& \text { where } \gamma_{1}=\frac{\sigma_{u}^{2}-4 \rho_{c u} \sigma_{u} \sigma_{c}+3 \sigma_{c}^{2}+\Theta}{4\left(\sigma_{u}^{2}-2 \rho_{c u} \sigma_{u} \sigma_{c}+\sigma_{c}^{2}\right)}>1 \\
& \text { and } \Theta=\sqrt{\left(\sigma_{u}^{2}-\sigma_{c}^{2}\right)^{2}+8\left(\mu-\rho_{c u} \sigma_{u} \sigma_{c}\right)\left(\sigma_{u}^{2}-2 \rho_{c u} \sigma_{u} \sigma_{c}+\sigma_{c}^{2}\right)}
\end{aligned}
$$

as the critical (trigger) value $\Gamma^{*}$. From the definition of $\Gamma$ it then follows that

$$
\left(\frac{\eta_{u}}{\eta_{c}}\right)^{\star}=\sqrt{\frac{2 \mu+\sigma_{u}^{2}-4 \rho_{c u} \sigma_{u} \sigma_{c}+\sigma_{c}^{2}+\Theta}{2\left(\mu-\sigma_{c}^{2}\right)}}
$$

is the trigger value of relative inflation preference parameters $\frac{\eta_{u}}{\eta_{c}}$ separating the region in $\left(\eta_{u}, \eta_{c}\right)$ space where country $c$ 's option of monetary disintegration remains unexercised (i.e. for $\left.\frac{\eta_{u}}{\eta_{c}} \leq\left(\frac{\eta_{u}}{\eta_{c}}\right)^{\star}\right)$ from the one where immediate exercise of that option is perceived as optimal (i.e. for $\left.\frac{\eta_{u}}{\eta_{c}}>\left(\frac{\eta_{u}}{\eta_{c}}\right)^{\star}\right)$.

\footnotetext{
${ }^{8}$ This adopts the solution strategy in Dixit/Pindyck (1994, p. 210).

${ }^{9}$ Thus, $\Gamma=\frac{\mu-\sigma_{c}^{2}}{\mu-\sigma_{u}^{2}}\left(\frac{\eta_{u}}{\eta_{c}}\right)^{2}$ from eq. (4).

${ }^{10}$ The geometric Brownian motion $\Gamma$ has an absorbing barrier at zero.
} 


\section{References}

[1] Barro, R.J., 1983, Inflationary finance under discretion and rules, Canadian Journal of Economics 16(1), 1-16.

[2] Barro, R.J. and D.B. Gordon, 1983a, Rules, discretion and reputation in a model of monetary policy, Journal of Monetary Economics 12(1), 101-121.

[3] Barro, R.J. and D.B. Gordon, 1983b, A positive theory of monetary policy in a natural rate model, Journal of Political Economy 91(4), 589610.

[4] Culver, S.E. and D.H. Papell, 1997, Is there a unit root in the inflation rate? Evidence from sequential break and panel data models, Journal of Applied Econometrics 12(4), 435-444.

[5] De Grauwe, P., 2003, Economics of monetary union, 5th. ed. (Oxford University Press, Oxford UK).

[6] Dixit, A.K., 1993, The art of smooth pasting (Fundamentals of pure and applied economics vol. 55) (Harwood Academic Publishers, Amsterdam).

[7] Dixit, A.K. and R.S. Pindyck, 1994, Investment under uncertainty (Princeton University Press, Princeton NJ).

[8] Lai, K.S., 1997, On the disparate evidence on trend stationarity in inflation rates: A Reappraisal, Applied Economics Letters 4(5), 305-309.

[9] OECD, 2003, OECD Economic Outlook No. 73 (Organisation for Economic Co-operation and Development, Paris).

[10] Strobel, F., 2001, When to leave a monetary union?, Revue Economique $52(2), 389-397$.

[11] Strobel, F., 2002, Leaving a monetary union: expected time and probability, Greek Economic Review 22(1), 17-22. 
[12] Strobel, F., in press, Monetary integration and inflation preferences: a real options analysis, European Economic Review. 